\title{
SAUCEROS, CRIOLLOS Y COLONOS EN LAS LLANURAS SANTAFESINAS A MEDIADOS DEL SIGLO XIX
}

\author{
SAUCEROS, CRIOULOS E COLONOS NAS PLANÍCIES SANTAFESINAS, \\ EM MEADOS DO SÉCULO XIX
}

\author{
Aldo Gastón Green \\ FHUC-UNL
}

\section{Resumen}

En este artículo se intenta indagar sobre las relaciones interétnicas establecidas entre los abipones de la reducción del Sauce y sus vecinos criollos e inmigrantes europeos en la segunda mitad del S. XIX. La conflictividad evidenciada entre indios y colonos europeos, y la frecuencia con que se producen episodios violentos que enfrentan a miembros de ambas colectividades, es analizada a partir de la coexistencia de modos de vida y de pensamiento contrapuestos, y de la fuerte estigmatización que pesa sobre el grupo indígena; en un contexto de competencia por el espacio y los recursos, que tiene por base el desajuste entre el ideario de los promotores de la colonización agrícola -en el marco del proceso de conformación y expansión estatal -y una realidad que no se condice con la imagen de un "territorio inhabitado".

Palabras claves: Relaciones interétnicas. Indígenas. Colonos.

\section{Resumo}

Neste artigo tenta-se indagar a respeito das relações interétnicas estabelecidas entre os índios abipones da redução de Sauce e os seus vizinhos crioulos, assim como com os imigrantes europeus na segunda metade do Século XIX. O conflito evidenciado entre os indígenas e os colonos europeus e a frequência com que se produzem os fatos violentos que confrontam os membros de ambas as coletividades são analisadas partindo da coexistência de formas de vida e de pensamentos contrapostos e da forte estigmatização que paira sobre o grupo indígena num 
contexto de concorrência pelo espaço y pelos recursos, que tem como base o desencontro entre o ideário dos promotores da colonização agrícola - no contexto do processo de conformação e expansão estatal - e uma realidade que não se ajusta com a imagen de "território despovoado".

Palavras-chave: Relações interétnicas. Indígenas. Colonos.

\section{Introducción}

En este artículo procuraremos indagar sobre las relaciones interétnicas entabladas durante la segunda mitad del s. XIX entre los indios abipones de la reducción de San Jerónimo del Sauce, ubicada en las llanuras del centro oeste de la actual provincia argentina de Santa Fe, y sus vecinos criollos e inmigrantes europeos. Intentaremos analizar particularmente la conflictividad que se advierte entre los indígenas y estos últimos, que irán conformando colonias agrícolas en la región a partir de 1856.

Dichas relaciones se producen en el marco del proceso de formación y expansión territorial del Estado argentino, que implicó para los indígenas abipones el sometimiento a una situación de dominación externa. En efecto, el Estado en construcción, avanza en este caso sobre el grupo étnico -que había logrado mantenerse independiente de la dominación española, aun formando reducciones $-\mathrm{y}$ sobre sus tierras (y recursos) imponiendo en ellas su aparato normativo institucional y represivo.

Quienes dirigieron ese proceso percibían al territorio como un desierto que debía ser poblado. Para eso, resultaba indispensable fomentar la inmigración de europeos e impulsar la colonización agrícola; asegurando a estos el acceso a la propiedad de la tierra. Estos objetivos estaban presentes en la Constitución de 1853, y la provincia de Santa Fe, especialmente, estuvo a la cabeza de la concreción de ese proyecto.

\section{San Jerónimo del Sauce}

El Sauce, pequeño asentamiento de ranchos de paja ubicados en torno a un cantón de frontera, presentaba un aspecto desolador a la mirada de los viajeros extranjeros que a mediados del siglo XIX recorrían las llanuras del centro oeste santafesino; uno de estos, el cónsul ingles Hutchinson, que lo visitó en 1863, anotaba que "No hay en el pueblo ningún establecimiento público, excepto una iglesia que por su vista tenebrosa, si no fuera por la cruz 
y campana, podría ser confundida con una cárcel” (HUTCHINSON, 1945, p. 189). Si el observador europeo no encuentra señales de lo que considera actividades productivas -ve un escaso desarrollo de la ganadería, y nulo en lo que refiere a la agricultura -las de la lucha fronteriza contra los indios del Chaco no le resultan desapercibidas; “...como a doscientas varas atrás de la iglesia -escribió - hay un cuadro, rodeado por un hondo foso, que se me dice es usado como fortaleza de refugio, en caso de alguna invasión de los indios salvajes." (HUTCHINSON, 1945, p. 189). Todavía en la década del 70, al hacerse cargo de la atención religiosa de la población el franciscano Caloni, esta “...casi estaba sin vida...” según sus propios dichos; él mismo hizo levantar dos escuelas (una para niños, y otra para niñas) de material, cercar una plaza con postes de ñandubay y alambre y plantar en ella paraísos. En los 80, el pueblo contaba ya con “...cinco casas de azotea, seis o siete de material y dos casas fuertes de Tienda y Almacén..." (CALONI, 1884, p. 59). Presentado por el misionero como un progreso debido a su propia actividad, esto resultaba sin embargo insignificante, comparándolo en los mismos términos con otras poblaciones de la zona.

\section{1. a) Los abipones sauceros}

Otra característica hacía del Sauce un enclave particular en la región que se iba transformando velozmente en la "pampa gringa"; durante buena parte de la segunda mitad del siglo XIX, el paraje estuvo poblado principalmente por indios abipones, grupo étnico que había formado allí una reducción en 1825.

Si la autoadscripción resulta un rasgo crucial para la identificación de los grupos étnicos ${ }^{\text {ii }}$ (BARTH, 1976), enfrentamos, en este caso, el obstáculo de encontrarnos frente a un grupo extinto y de no contar prácticamente con testimonios directos de los propios actores. Tenemos, en cambio, abundantes informes de militares, viajeros, curas, etc. de la época en que estos indios aparecen categorizados externamente. Dependiendo del tipo de contacto o conocimiento que tuvieran de ellos quienes produjeron esas referencias, observamos que se les aplicaban diversos rótulos: "indios", “indios del Sauce”, “indios lanceros”, "lanceros”, "sauceros" o "abipones".

El escollo señalado puede sortearse a partir de la información de los libros parroquiales, que nos acerca a las voces indígenas. En los registros de matrimonios, bautismos 
o defunciones realizados en las reducciones por los curas, estos consignaban muchas veces el origen étnico de las personas. Si el rótulo de "indio", que aparece en la mayoría de las actas, podía ser impuesto a partir de la observación de algún rasgo externo considerado como marca identitaria en la época; el de "abipones" dependía en gran medida del interrogatorio realizado a los contrayentes, padres, padrinos, o parientes del muerto; y solo podía surgir de esta indagatoria cuando se trataba de indios sauceros dispersos en asentamientos no abipones, como Concepción de Reconquista o Santa Rosa de Calchines (reducciones de indios mocovíes); ya que todos eran igualmente "indios" para los curas que, en general, permanecían cortos períodos entre ellos.

En 1899 en Concepción de Reconquista, donde junto a los mocovíes se había instalado un contingente de abipones sauceros, el cura Iturralde escribía que a los indios: "casi no se los distingue sino por el tipo, pues han adoptado el lenguaje, modo de ser y costumbres de los demás habitantes" (citado en ALEMÁN, 1997, p. 147). La fisonomía, a partir de la cual Iturralde pretendía reconocer a los indígenas, no le permitía distinguir entre abipones y mocovíes. Para la mirada externa se trataba de "indios" y así se los registraba en los libros parroquiales. Es evidente que, en algunos interrogatorios prenupciales o a parientes del muerto, la categoría "abipon", que aparece en las actas de Reconquista, formaba parte de la respuesta de los propios actores a la pregunta sobre su origen ${ }^{\mathrm{iii}}$; y que en la segunda mitad del s. XIX los abipones se autorreconocían como tales.

Aunque podríamos hacer un listado de sus rasgos culturales contrastantes (que diferiría de uno similar para los abipones del siglo XVIII), este no resultaría determinante para constatar su persistencia como grupo étnico en la segunda mitad del s. XIX. Debemos referirnos, sin embargo, a un aspecto de su cultura que será importante al momento de analizar las características que revistieron las relaciones interétnicas en la zona.

Si bien la subsistencia de los indios del Sauce dependía en cierta medida del racionamiento que recibían del Estado a cambio de sus auxilios militares como "lanceros", que tenía también una compensación monetaria, continuó revistiendo de suma importancia la práctica de la caza y recolección; como lo muestran abundantes documentos y referencias de viajeros.

No habíamos andado mucho cuando los indios de lanza, obedeciendo a su pasión dominante, organizaron una cacería" relataba Mac Cann a mediados de siglo (MAC CANN, 1939, p. 189). Las presas atrapadas en esa ocasión, dos gamos, se compartieron entre todos, 
quedándose el cazador que había atrapado al primero solo con la cabeza. Años después, Mantegazza se lamentaba: "Es muy difícil persuadirlos al trabajo; escasos de necesidades y apasionados por la independencia y el ocio, prefieren estar echados todo el día sobre sus pieles y no levantarse más que de cuando en cuando, para cazar avestruces y gamos (MANTEGAZZA, 1916, p. 265).

Estas actividades implicaban expediciones más o menos prolongadas, realizadas por pequeños grupos, en un amplio espacio cuyos contornos pueden delinearse con bastante precisión a partir de referencias documentales o de tradiciones orales ${ }^{\text {iv }}$. Hacia el norte del mismo, en las cercanías del arroyo Cululú, los sauceros iban sobre todo en busca de miel de lechiguanas y existen indicios de que solían bolear yeguas, gamos y ñandúes en la zona de las Tunas, al noreste del Sauce. Aunque al Oeste, el principal campo de caza parece haber estado en torno a Piedra Blanca, sus correrías llegaban hasta las cercanías de Quebracho Herrado en el límite con la provincia de Córdoba. La base de este dilatado terreno de caza estaba constituida por la zona poblada de estancias y campos privados que se extendía al sur del cantón del Sauce. Consecuentemente con este modo de subsistencia había persistido -aun cuando la mayoría de los indios vivía en el pueblo - un patrón de asentamiento disperso y no era extraño que familias o pequeños grupos vivieran desparramados por el campo. Se trataba en rigor de un territorio fronterizo que hacia mediados de siglo se hallaba poco poblado por criollos y débilmente controlado por el Estado; control escaso que dependía, por otro lado, de la alianza con los indios del Sauce y de su auxilio militar.

\section{1. b) Los criollos}

El Sauce también contaba con un componente criollo representado principalmente por los soldados del cantón y sus familias. Algunos llevaban viviendo largo tiempo en la localidad -ya aparecen en las listas de dragones (soldados que portaban armas de fuego) en las décadas del 30 y 40 -mientras que otros habían llegado en épocas posteriores como presos remitidos por el gobierno para que cumplieran sus penas en la frontera, según se desprende de diversos documentos: como una nota de 1855 en la que un oficial denuncia la deserción de Manuel Acosta, señalando que “....este soldado es de los últimos de unos cinco presos que me dio Uv. 
Que hera del Rosario" (AGPSF. Archivo privado de José Rodríguez, caja 1, legajo O, f. 10); u otra de 1869 , en la que el gobierno ordena al jefe de policía de la capital que ponga

a disposición del Mayor Deniz los individuos Dionisio Toledo, Juan Carranza y Antonio Hernandez con destino al servicio de la frontera remitiendo desde ya los dos primeros al referido mayor y el último cuando el lo solicitev. (AGPSF. Copiador de notas del Ministerio de Gobierno, 186870, T. 51, f. 152)

Aunque prestasen servicios en otros cantones cercanos -Zarate, Ramada, Corrales, etc. - estos soldados criollos solían asentarse definitivamente en el Sauce o seguían vinculados a la población, como puede comprobarse a partir de los libros parroquiales de la iglesia del lugar, en los que se registran sus matrimonios -a veces con mujeres indias ${ }^{\mathrm{vi}}$-, los bautismos de sus hijos y sus defunciones.

Además de los soldados, había un heterogéneo abanico de pobladores no indios, que en algunos documentos de la época aparecen como "becinos", establecidos en el Sauce o en parajes rurales o estancias cercanas. Peones, capataces, puesteros, pulperos, simples "transeúntes" o "ambulantes" que pasaban o se instalaban por algún tiempo en el lugar, desertores, individuos que tenían cuentas pendientes con la justicia o entrados ilegalmente a la provincia; eran, al igual que los soldados, de los orígenes más diversos, y formaban parte de los sectores subalternos de la sociedad estatal.

Algunos criollos se dedicaban a la ganadería, poseyendo "acienditas" de pocos animales, vacas lecheras principalmente; "y esto tenemos alguno de a diez, 20, 30, cuarenta y sincuenta, y los mas unos cuatro, otros seis, otros nueve o diez" (AGPSF, A. de G. T. 31. 1867, f. 1301), reportaba Eulogio Castañeda al gobierno en 1867. Otros podían emplearse como peones en las estancias, o ser contratado por el Estado para trabajos particulares. Los soldados tenían su paga y raciones. A diferencia de lo que ocurría entre los abipones sauceros, la caza debió ser el último recurso en situaciones de miseria. Esto puede comprobarse en la impericia que por lo general se notaba para dicha actividad. Un oficial del cantón Barco comunicaba que "dos soldados se han desgraciado, uno se há quebrado el muslo y el otro se há sacado el tobillo, de hambre salieron al campo a correr y rodaron, porque hace cuatro días que estamos sin carne" (citado en GORI, 1972, p. 61). 


\section{1. c) De la reducción india al pueblo criollo}

La población total de la reducción del Sauce osciló en torno a los 600 habitantes hasta la década del 60; en 1865-1867 sumaba, según un censo levantado por Fray Antonio Rossi, las 564 personas y hacia 1882 se consignaba una disminución de la población que luego se recupera para el censo de 1895 (CALONI, 1884). Es más difícil establecer cuantitativamente la distribución étnica de sus habitantes; el coronel Du Graty contabilizaba en 1854, 36 soldados de línea, 14 milicianos y "120 indios de pelea" con sus familias (AUZA, 1971, p. 173), pero esta proporción se fue invirtiendo. El componente indio se redujo gradualmente a causa de las epidemias y las luchas contra los "montaraces", como se denominaba a los que permanecían hostiles a la sociedad criolla al Norte de la frontera; tanto como por la agudización del mestizaje y la dispersión en los fortines. Desde luego estas vicisitudes también afectaron a la población criolla, pero esta contaba con la posibilidad de renovarse y continuó afluyendo al punto desde diferentes lugares.

En los censos de la República Argentina de 1869 y $1895^{\text {vii }}$ se encuentra, en la columna correspondiente a "nación" de los padrones del Sauce, los rótulos de "argentina", "italiana", “alemán", "Brasil", etc.; no apareciendo en ningún caso los de "indio" o "abipón”. No obstante, cruzando la información de las boletas censales con la proveniente de listas de lanceros y de los libros parroquiales de la localidad, o de otras como Reconquista o Calchines, entre otras fuentes; podemos identificar a las familias indígenas y estimar la población de sauceros para esa época.

En 1869, sobre un total de 600 habitantes del Sauce, los indios eran poco menos de la mitad. A fines de los 80 los criollos, entre los que había residentes de instalación reciente, y los mestizos predominaban sobre aquellos, e incluso podía encontrarse en el distrito pobladores de origen extranjero.

En el censo de 1895, sobre 203 habitantes del área urbana de San Jerónimo del Sauce, podemos estimar 66 indígenas, 122 criollos y 15 extranjeros; mientras en el área rural, sobre 547 habitantes, identificamos a unos 40 indios, 162 extranjeros y el resto de "argentinos" (incluyendo hijos pequeños de padres extranjeros). 


\section{1. d) Las relaciones entre sauceros y criollos}

La interacción de los indios sauceros con los pobladores criollos de la zona, como su posterior relación con los colonos extranjeros, se produce en el marco de su progresiva subordinación a la sociedad estatal. A partir de la segunda mitad del siglo XIX, la presencia del Estado en esos territorios fronterizos, considerados tierras fiscales, se ira consolidando paulatinamente y llevando a la implementación, cada vez más efectiva, de un marco jurídico institucional ajeno a los sauceros que los habitaban.

Si la creación de la reducción en 1825 marcó el início de la alianza de los abipones con el Estado provincial y de su convivencia pacífica con los criollos, fue en la década del 40 que esta relación comenzó a consolidarse, no registrándose, a partir de la misma, tensión entre los miembros de ambas colectividades.

Los conflictos entre individuos eran muy comunes en el distrito, como variados los motivos que los generaban; desacuerdos por apuestas, discusiones en estado de ebriedad, robos, etc. y lo corriente era la resolución violenta de los mismos, como queda ampliamente evidenciado en diversa documentación de la época ${ }^{\text {viii }}$. Los numerosos altercados particulares producidos en el Sauce y alrededores en la segunda mitad del s. XIX no reconocían, sin embargo, un patrón de enfrentamiento étnico entre indios y criollos. Por el contrário, se torna visible, desde mediados de siglo, el surgimiento de lazos de amistad y parentesco entre ellos. La participación conjunta en las expediciones realizadas contra las tribus hostiles del norte de la frontera; la vida común en los fortines y la sociabilización en otros ámbitos como las pulperías -que eran así mismo el escenario de muchos de los incidentes señalados - podían brindar la ocasión para el surgimiento de lazos estrechos entre individuos de ambas colectividades.

En los libros parroquiales, además de los matrimonios mixtos ${ }^{\mathrm{ix}}$, se registran casos de compadrazgo, vínculo que en ocasiones se veía reforzado por su repetición ${ }^{\mathrm{x}}$ y que en la época generaba una relación estrecha, creando obligaciones especiales entre los compadres, y entre padrino y ahijado. Aunque el compadrazgo es una institución de origen occidental, los sauceros compartían este significado, ya que el proceso de aculturación estaba bastante 
avanzado en la segunda mitad del siglo, favorecido precisamente por la estrecha convivencia entre indios y criollos y por el progresivo predominio demográfico de los últimos.

Si bien las dicotomías étnicas comportan diferencias culturales, no es el conjunto de "similitudes" y "diferencias" observables externamente, lo relevante para su permanencia, sino aquellos rasgos que los propios actores consideran significativos (BARTH, 1976). Más allá de los elementos culturales comunes a sauceros y vecinos criollos de la zona, durante la segunda mitad del siglo se distinguía con nitidez a ambas poblaciones. No solo en documentos producidos por agentes del Estado o por personas ajenas al distrito; incluso los propios jefes indios se encargaban en sus notas y comunicaciones al gobierno de diferenciar a sus "avispones", "lanceros" o "indiadas" de los "besinos" o "tiradores". Esta distinción, asumida por los propios actores, no parece haber tenido, en virtud de lo antes señalado, una connotación negativa en la zona. Sin embargo, fuera de esta y de parte del Estado especialmente, implicaba tratos diferenciales en detrimento del conjunto "indio" sobre el cual pesaba una fuerte estigmatización. Esta consiste, según Colombres, en el señalamiento de las diferencias entre colonizados y colonizadores; la valoración de estas en benefício del colonizador; y su traslado al campo de lo absoluto, presentándolas como definitivas y actuando como si lo fueran en realidad. Contribuye a quitar a las minorías étnicas de los caminos de la competencia y utilizarlas para promover el desarrollo ajeno (COLOMBRES, 1976, p. 32-33).

Podemos encontrar esta visión negativa sobre los indígenas en las opiniones de un promotor de la colonización como Amadeo Jacques ${ }^{\mathrm{xi}}$, tanto como en las de un misionero franciscano que visitaba la reducción del Sauce ${ }^{\text {xii }}$; o en la nota de un funcionario menor del Estado que al listar a los presos que se encuentran en la cárcel de Santa Fe por sus nombres y apellidos, refiere a cinco soldados indios del Sauce, de quienes no anota los nombres, con el rotulo colectivo de "Dementes" (AGPSF. A. de G. T. 25, 1864, f. 70-72).

\section{Sauceros y colonos}

2. a) El asentamiento de los colonos europeos en la zona

En la segunda mitad del siglo XIX comenzó, como es sabido, la llegada de inmigrantes europeos al territorio de la Confederación Argentina en conformidad con el vasto 
proyecto modernizador encarado por las elites dominantes. La afluencia de estos al país se creía indispensable para ese fin; y se fomentaba la inmigración para poblar un territorio que se percibía como desierto.

Con la fundación de la colonia Esperanza en 1856 la provincia de Santa Fe se convirtió en pionera de la colonización agrícola; los inmigrantes recibieron concesiones de 33 2/3 ha. que debían pagar en cinco años con el tercio de la cosecha, aunque el gobierno termino haciéndose cargo de sus deudas en muchos casos. Se los recibió con ranchos casi terminados; semillas y animales, reembolsables en dinero a los dos años, o a los tres si había malas cosechas; y víveres hasta la venta de las mismas; se los exceptuó, finalmente, de contribución y del servicio militar, aunque podían formar guardias de rifleros. A partir de esta experiencia exitosa, la colonización por inmigrantes europeos y la privatización y subdivisión de la tierra se extendieron por el centro oeste de la provincia al compás de las ventajas ofrecidas por el apoyo estatal y luego el mercado internacional. A Esperanza siguieron San jerónimo (1858) y San Carlos (1859) y en una segunda etapa surgieron Humboldt (1868), Las Tunas, Grütly (1869), Santa María etc. (OGGIER y JULLIER, 1984; DU GRATY, 1968).

Como consecuencia de este proceso fundamental en la construcción de la Argentina moderna, que ha sido presentado frecuentemente en términos de gesta tanto por la literatura como por trabajos historiográficos ${ }^{x i i i}$, el Sauce quedo rápidamente cercado por el frente colonizador agrícola y por tierras de propiedad privada. En un informe fechado en 1875 se ve que el terreno asignado a la reducción era de 1 legua, la mitad de la cual estaba dividida en concesiones. Al norte de ese estrecho espacio se hallaban los campos de J. P. López y la colonia de San Gerónimo de 4 leguas. La colonia de las Tunas se hallaba al noreste, y al este estaban la Unión Agrícola con 3 leguas, y la de San Agustín; al sudeste la colonia San Carlos de 6 leguas, al sur la colonia Lubary de 2 leguas, y al oeste los campos de Sa Pereira y de los hijos del cacique Denis (AGPSF. Libro de informes al Exmo. Gobierno. Topográfico, T. 44, fs. 263-270).

Gori ha insistido en que los terrenos en los que fue fundada la colonia Esperanza no eran territorios habitados por indios, ya que las tolderías de los montaraces se encontraban más al norte y que el único asentamiento indio de la zona estaba constituido por el pequeño poblado del Sauce (GORI, 1972), razonamiento que podría extenderse a las otras colonias mencionadas. Esta percepción del espacio no es otra, en realidad, que la de los promotores de la colonización agrícola, para quienes territorio habitado era igual a pueblos, caminos y 
campos cultivados. Considerando, sin embargo, la cultura y el modo de subsistencia tradicional de los sauceros no se trataba de una zona inhabitada. Las colonias mencionadas se extendieron precisamente sobre el territorio de caza y recolección de aquellos, y que hemos delimitado atrás. Se trataba por lo tanto de un espacio recorrido, explotado y vivido por estos indígenas desde antes, incluso, de la conformación del Estado argentino.

\section{2. b) Las relaciones entre índios y colonos}

Existen en la historiografía local dos visiones contrapuestas acerca de las relaciones que se entablaron entre colonos e indios -particularmente los del Sauce -en el centro oeste santafesino durante la segunda mitad del siglo XIX.

Algunos trabajos enfatizan el carácter amigable de las mismas e insisten en la cooperación entre ambos grupos, lo que no encuentra respaldo documental (ROSELLI, 1983; LÓPEZ ROSAS, 1993; LANCE y PEDRONI, 1999). Oggier y Jullier, que presentan una variante de este punto de vista, señalan que, si bien no se produjeron grandes fricciones, tampoco hubo una relación estrecha entre los sauceros y los colonos de San Jerónimo Norte; y que en realidad existen muy pocas noticias de la presencia de los primeros en dicha colonia. Entre los incidentes mencionan un hecho producido el 17 de abril de 1864, cuando algunos sauceros, entre los que había familiares del jefe Denis, concurrieron a la colonia y a la pulpería de Andrés Sibori a realizar algunas compras. Sospechando que le robaban este "trató a los hijos del Mayor Denis de ladrones y pícaros, amenazando a todos de correrlos a tiros si no se iban al instante y que los enviaría a Santa Fe "atados como un Cristo"” (OGGIER y JULLIER, 1984, p. 115). Ante la agresión los indios se marcharon respondiendo a los insultos y abandonando, en su apuro, incluso la plata. Este suceso, que no fue un altercado aislado como han pretendido los autores, es una muestra del rechazo generalizado de los colonos hacia la presencia de los indios en las colonias y puede contribuir a explicar su escasa o nula aparición en estas; en las que sí encontramos a criollos como habitantes o peones (GORI, $1948 ; 1972)$.

Quienes, a diferencia de los autores anteriores, reconocen la existencia de una relación tensa o señalan especialmente el enfrentamiento, lo explican como resultado de los continuos robos y delitos cometidos por "gauchos" e indios y de los cuales eran víctimas los habitantes 
de las colonias agrícolas, que a veces reaccionaban de manera violenta. Según Gori, el conflicto pasaba por ser el Sauce lugar donde encontraban amparo "malhechores no indios" y por los hechos delictivos "provocados por algunos de sus elementos", "que formaban una especie de bajo fondo de la Pampa" (GORI, 1972, p. 29-30). El uso de la violencia por parte de los europeos, y sus acciones "a veces tan bárbaras como las acciones de los indios" (GORI, 1972, p. 12) habría tenido siempre el carácter de reacción, en ocasiones exagerada, en defensa de sus propiedades; según esta más o menos explícito en este tipo de planteos (GORI, 1972; GSCHWIND, 1994). Esta era, por otro lado, la explicación que los propios colonizadores daban de su accionar; cuando en 1869 un nutrido grupo de colonos sancarlinos irrumpió en el Sauce y disparando a mansalva asesino a Nicolás Denis y a su vecina Candelaria Araujo, el empresario de la colonización Beck Bernard no dudo en atribuir el hecho a la "exasperación" de aquellos, frente a los continuos delitos cometidos por indios y bandidos a quienes Denis brindaba protección (GSCHWIND, 1994, p. 278-279).

Esta afirmación hecha sobre el jefe de los indios por un empresario interesado en justificar de alguna manera el crimen, contrasta con otra documentación existente, como los frecuentes partes enviadas por el propio Denis al gobierno acompañando la remisión, a la cárcel de la capital, de bandidos atrapados por sus lanceros.

Si las quejas y denuncias por parte de los colonos abundan y encuentran eco en empresarios, políticos y militares, no existen prácticamente descargos de parte de los indios; en tal sentido la nota enviada por Feliciano Denis, jefe de estos, al gobernador Servando Bayo en noviembre de 1875 es única. En esta le comunica que 65 colonos de la colonia Santa María y otras vecinas habían atacado el fortín Sunchales, donde los sauceros prestaban auxilio, viéndose obligado el oficial al mando a abandonarlo y retirarse a una cierta distancia. El motivo alegado por los colonos era el consabido y Denis niega las acusaciones que pesaban sobre su gente estos colonos inculpan a mis soldados que les roban (...) cuando no hay tal y por todo corre que estos son á quienes les roban; es en atención de esto que yo en nombre de este pueblo reclamo el credito de mi gente (AGPSF, A de G. T. 42,1875, f. 1711).

Cuando los inmigrantes europeos descubrían a los indios robándoles o en actitudes sospechosas reaccionaban violentamente; dos años después de fundada la colonia Esperanza, el 24 de abril de 1858, el colono Schneider disparo su escopeta sobre tres sauceros que, de noche, estaban sacando batatas en la concesión vecina de Rey Ulrich “...habiendo uno de dhos tiros herido mortalmente al Indio reducido Santiago Liniers al tiempo de acercarse este 
gritando que se rendia." (AGPSF, A. de G. T. 17, 1858, f. 833). Este murió días después a causa de las heridas y Gabarret, juez de paz de la colonia condeno moralmente su asesinato, ya que su delito "...si bien es punible, no demandaba por cierto un castigo tan cruel." El asesino fue detenido tres meses después, pero por el delito de golpear al comisario de la colonia, manifestando el mismo Gabarret que "El hecho escandaloso que acaba de perpetrar requiere ser reprimido con todo rigor" (AGPSF, A. de G. T. 17, 1858, f. 831).

Matar indios, aunque fueran reducidos y cumplieran funciones militares para el Estado, como era el caso de Santiago Liñero, no parece haber constituido un delito, e incluso podía llegar a ser motivo de orgullo y privilegios; aun a fines de la década de 1870, en Grütly, se gratificaba con tierras a "los tres célebres cazadores de indios Arnoldo Reutimann y los hermanos Lottersberger" (citado en BERLI, CAMARA y ZURBRIGGEN, 1981, p. 26). La justificación de tales hazañas era siempre la misma, se trataba de "ladrones".

Sin embargo algunos enfrentamientos o altercados no podrían atribuirse a una reacción de los colonos ante un delito, pues se producen antes de que este se cometiera; hemos visto el trato de Síbori a los hijos de Denis, y este parece ser el caso también de la expulsión de Grutly del "bandido Perico, Negro o indio del Sauce" (AGPSF, A. de G. T. 35, 1870-1871, f. 1202) a inicios de 1870; es evidente que no había cometido un crimen ya que de lo contrario lo hubieran apresado y remitido a Santa Fe, o tomado alguna medida más drástica, como también lo es que para los colonos era cuestión de tiempo para que lo cometiera puesto que se trataba de un "bandido". Esta prevención generalizada respecto de los indios era traída muchas veces de la misma Europa y respaldada por la imagen negativa, difundida a través de cartas y relatos orales, que les atribuía toda clase de vicios y fechorías, y que no estaba muy alejada de la que se tenía en el país como parte de su estigmatización. Se ha sugerido que este recelo y el temor de los inmigrantes respecto de los sauceros contribuyen a explicar el accionar violento de los colonos, discutiéndose, además, si eran fundados o infundados (BERLI, CAMARA y ZURBRIGGEN, 1981). Lo cierto es que ésta prevención resulto funcional a la resolución del conflicto de fondo, a favor del frente colonizador.

El rechazo de la presencia india en las colonias fue general, pero esto no puede atribuirse solo a los prejuicios. En enero de 1859, 6 indios y una india de la reducción del Sauce se encontraban buscando lechiguanas en la zona noroeste de la colonia Esperanza, 
terreno que en ese entonces caía dentro de la concesión de un colono de nombre Jacob. Al ser descubiertos, comunica Gabarret al gobierno; "acudieron presurosos unos 50 colonos con rifles, no sabiendo los mas de ellos errar un solo tiro a un alcance de 500 varas", intimaron a los indios a detenerse, pero tres montaron a caballo y huyeron "lo que viendo un colono disparó un escopetazo del que me han asegurado salió herido uno de los prófugos". La mujer y los tres que se quedaron fueron interrogados y a pesar de que uno de ellos, llamado Pascual, presento una nota dirigida por el capitán José Barcos al comandante general Montiel, probando así que se hallaban además prestando auxilios al gobierno, se les recomendó que "no viniesen a la colonia ellos ni tampoco los demas compañeros del Sauce" (AGPSF, A. de G. T. 18, 1859, f. 1412).

La caza y recolección revestía, como señalamos, de importancia para los abipones y se desplegaba sobre un amplio territorio. A medida que este fue siendo ocupado por los europeos, las expediciones con esta finalidad se tornaron fuente de altercados que como en el caso citado no pueden explicarse simplemente a partir de la reacción o prevención por parte de los colonos frente a los "abusos" de los sauceros. En efecto, en esta ocasión solo estaban recolectando miel en una zona que explotaban tradicionalmente y la presentación de la nota por uno de ellos debió alejar cualquier sospecha de que se tratara de ladrones; en realidad cumplían funciones militares, pero aun así se los expulso de esos terrenos que habían pasado a ser propiedad privada y se les advirtió que en adelante no regresaran, ni ellos ni los demás del Sauce.

La explotación de un mismo territorio por parte de grupos culturalmente diferentes, más que cualquier prevención, parece haber sido en este caso la causa principal del incidente. Esto puede visualizarse mejor en un tipo de altercado bastante común, y que la tradición oral ha retenido; un colono de la zona de San Agustín afirmaba que los indios solo se tornaban agresivos cuando los inmigrantes les mataban los caballos que se acercaban a beber agua en sus propiedades estropeando los sembradíos (LANCE y PEDRONI, 1999, p. 78). Los daños que las tropillas de caballos o la hacienda producían comiendo o pisoteando los cultivos fueron además una fuente constante de enfrentamiento entre estos y los hacendados criollos y peones gauchos de las estancias vecinas, aunque en estos casos los europeos se limitaban a hacer sus reclamos al gobierno ${ }^{\text {xiv }}$. También era común que los colonos llevaran a pastar a sus propios animales a las estancias vecinas (OGGIER y JULLIER, 1984). 
Esto último, nos sugiere que la diferencia cultural fundamental entre sauceros y colonos no radicaba en la defensa o no del principio de la propiedad privada. No podemos explicar los incidentes producidos entre los diferentes grupos como simple resultado de la reacción de los europeos en defensa de esta; por el contrario, estos tomaron la iniciativa en muchos casos, con acciones que bien podrían considerarse, según su propia concepción, como abusos o delitos contra la propiedad ajena.

En el sumario levantado por el juez de paz Gabarret, contra el ya mencionado Schneider, señala que:

de los colonos que carnearon ovejas pertenecientes al comandante Dn. Antonio Crespo, sin la voluntad del dueño, es el único que aun no ha abonado el valor de siete de estos animales que le corresponden según la relación pasada por el Juez de Paz mi predecesor (...) Creo saber de buena tinta que fueron mas de siete las ovejas que por su parte cazó furtivamente Schneider (AGPSF, A. de G. T. 17, 1858, f. 830).

Varias observaciones pueden hacerse a partir de este extenso documento; que Gori (1972) ha citado parcialmente para mostrar los abusos que solían cometer los indios del Sauce en las colonias, sin advertir estos otros sucesos consignados; en primer lugar, que a poco de fundada la colonia Esperanza, algunos inmigrantes se sustentaron en parte robando ovejas a Antonio Crespo, jefe de los indios sauceros; que a pesar de que este logro recuperar a través de la justicia parte de lo que le habían robado, la autoridad de la colonia actuó con negligencia, al no establecer el número exacto de animales robados, ni asegurar su total restitución. El hecho de que los que castigaron a Santiago Liñero fueran los mismos que habían robado a Antonio Crespo pone de manifiesto, por último, que no era la defensa de la propiedad privada en tanto "valor" lo que los motivaba; se trataba simplemente de una lucha por la apropiación de bienes y recursos; defendían los que consideraban propios y tomaban por la fuerza los que sabían ajenos según su propio modo de pensamiento.

Esta competencia no solo se daba con los indios, sino también con los hacendados y peones criollos de la zona, e incluso entre los mismos europeos, aunque en estos casos revestía formas menos violentas. Los hacendados solían denunciar a bandas de colonos 
armados que entraban a hurtar leña y paja a sus propiedades ${ }^{\mathrm{xv}}$, o que robaban y carneaban sus animales $^{\mathrm{xvi}}$.

En el caso de los indios, que en general no contaban con los títulos de propiedad correspondientes de las tierras que ocupaban ni con el respaldo del Estado, la competencia por el espacio solo podía inclinarse a favor de los inmigrantes. La queja de R. Gessler a nombre de los colonos de Grutly contra delitos cometidos por "bandidos" ilustra bien el processo:

Creo tener - dice - tanto mas derecho a la protección que solicito, cuanto al establecer la colonia Grutli hago desalojar a los bandidos de su guarida, conquisto diez leguas de terreno para la agricultura y aumento la riqueza y la población de la provincia (AGPSF, A. de G. T. 35, 1870-1871, f. 1202).

Es evidente que las tierras que formaron parte de Grutly no estaban deshabitadas ¿Acaso tuviera allí su morada el "indio Perico", antes mencionado? ¿Cómo subsistiría en una región tan alejada de campos y estancias sino fundamentalmente a partir de la caza? Desalojado de su tierra para la instalación de la colonia; el paso siguiente debía ser alejar al "bandido Perico" de la misma.

\section{Competencia por el espacio, diferencias culturales y estigmatización étnica}

Los episodios más o menos violentos que hemos mencionado a lo largo de este trabajo ponen en evidencia el choque entre grupos con diferentes modos de vida, que tiene como trasfondo una competencia por el espacio que parte de un desajuste entre el ideario de los promotores del proyecto colonizador y la realidad.

Efectivamente, la distancia cultural existente entre ambos grupos, podía generar conflictos; las partidas de indios entrando en campos privados para perseguir animales o recolectar miel, o sus caballos pisoteando los cultivos de los colonos; estos arando y sembrando en los antiguos territorios de caza de los indios o impidiéndoles acercarse a las aguadas - escenas que fueron frecuentes -lo demuestran. Pero el conflicto no fue el simple resultado de la vecindad de dos grupos que desarrollaban distintos tipos de actividades económicas: cazadores y agricultores. Es el contraste entre dos sistemas de pensamiento diferentes; que Barnard distingue como Modo de pensamiento del cazador recolector y Modo de pensamiento de acumulación, con sus implicancias sobre la relación con la tierra y los recursos (BARNARD, 2001); el que permite comprender la competencia que se va a entablar

\begin{tabular}{l|l} 
Revista RBBA & Revista Binacional Brasil Argentina
\end{tabular} 
entre sauceros e inmigrantes europeos en el medio oeste santafesino durante la segunda mitad del s. XIX.

Mientras los colonizadores practicaban una agricultura para el mercado, los sauceros cazaban y recolectaban para el autoconsumo; si en un caso el móvil era la acumulación; en otro, la obtención y distribución de los bienes estaba ligada a otros objetivos cuya pervivencia puede percibirse incluso en los pocos casos en que algunos indios se dedicaron a practicar una agricultura incipiente; el indio Cortes, explicaba a Mantegazza - que visito el Sauce a fines de la década del 50 -que había sembrado "pues no quería que ninguno llamase a su rancho y se volviese con las manos vacías" (MANTEGAZZA, 1916, p. 265). Barnard, precisamente, sostiene que para los cazadores recolectores "compartir tiene más valor que acumular" (BARNARD, 2001, p. 16). Esto último se concibe como una actitud antisocial y, en general, una vez que los cazadores han obtenido lo que necesitan, cesan su actividad y lo consumen inmediatamente. Los valores propios del modo de pensamiento de los cazadores recolectores pueden conservarse aun cuando se produzcan cambios en los medios de subsistencia (BARNARD, 2001, p. 27). Esta práctica de la caza y recolección, por otro lado, necesita para ser sustentable, explotar un territorio extenso, aunque no reclama un uso exclusivo. A mediados de siglo, los sauceros coexistían sin problemas con la escasa población criolla de la región y sus pequeñas explotaciones ganaderas. Al comienzo, ni siquiera debieron ver a los colonos como una amenaza, como lo muestra su cooperación en la construcción de los ranchos para la instalación de estos en Esperanza.

La búsqueda de la acumulación por parte de los europeos conducía en cambio a una actividad continua y expansiva. El colono no solo aspiraba a obtener el título de propiedad de la concesión que explotaba personalmente, sino también a expandirse y conseguir nuevas concesiones para su uso exclusivo. Este modo de pensamiento planteará inevitablemente una lucha por las tierras y los recursos. No se trataba simplemente de una reducción gradual de las tierras fiscales al sur de la frontera, donde su creciente demanda y consiguiente valorización hizo que incluso algunos grandes propietarios fraccionaran las suyas dando lugar al surgimiento de nuevas colonias. Aunque en la frontera norte se fueran incorporando nuevas tierras quitadas a los "montaraces", estas resultarían, según la lógica imperante, escasas a la larga.

\begin{tabular}{l|l} 
Revista RBBA & Revista Binacional Brasil Argentina
\end{tabular} 
La demanda de tierras se debió tanto a la afluencia de nuevos contingentes de europeos, como a la expansión de los ya radicados en la zona; el hecho de que muchos de los que compraron concesiones en las colonias de la segunda etapa provinieran de las tres colonias madres da cuenta de esta dinámica expansiva. Los límites de las primeras colonias pronto resultaron estrechos por que los hijos o yernos de los colonos buscaban formar sus propios hogares, pero también por la necesidad de inversión de las ganancias en nuevas explotaciones. En la colonia de Humboldt se extendieron en un solo día 221 escrituras de venta, cifra que según Gori "da la medida de la necesidad urgente de tierra que tenían los colonos de Esperanza" (GORI, 1948, p. 41) que constituyeron el 50 \% de los primeros colonizadores de esa. También obtuvieron tierras colonos de San Carlos y San Jerónimo y a los pocos meses resultaron escasos los 232 lotes originarios de Humboldt para satisfacer la demanda. Sin embargo, en numerosos casos el comprador no pobló personalmente la concesión (GORI, 1948; 1964).

El inmigrante concebía a la tierra y los recursos como escasos. Esto inspiraba sin duda el angustiado reclamo de los colonos de San Jerónimo ante el trazado de la colonia Humboldt -en cercanías de tierras que ellos pretendían anexar como campo de pastoreo para sus animales -por "especuladores" que "toman todo el campo" (OGGIER y JULLIER, 1984, p. 197), y los conflictos que también se producían entre los propios colonizadores; en 1870, los de San Jerónimo iban a buscar leña a los terrenos pertenecientes a los de Grutly que previenen que aquellos que lo hagan "serán tratados como ladrones" (OGGIER y JULLIER, 1984, p. 124). La competencia entre actores que compartían una misma cultura y reconocían un mismo marco regulador (aunque trataran de violarlo sin ser descubiertos) dio lugar a un interminable intercambio de denuncias y amenazas.

Aunque los sauceros estaban teóricamente comprendidos en ese marco, la estigmatización que pesaba sobre ellos les cerraba la posibilidad de valerse con éxito del mismo. Reducidos sus terrenos de caza tradicionales, también se los intento ceñir dentro de los límites de su reservación, impidiendo su circulación, sobre todo en las colonias o sus cercanías ya que su origen étnico los convertía en peligrosos y "ladrones", incluso en los casos en que las diferencias culturales no fueran tan notorias, como el de los hijos del cacique Denis. A esto apuntaba una orden general impartida en 1858 por el jefe militar de la frontera norte, que decía en su artículo $2^{\circ}$ : 
Todo indio o chino de las Colonias Indígenas ya sean de San Javier, Calchines, San Pedro o Sauce, que fuera encontrado a vanguardia de la línea de frontera... o a tres leguas a retaguardia de ella, sin un permiso escrito del Exmo. Gobernador de la Provincia o del jefe de las respectivas Colonias, será hasta un mes de la fecha de esta orden general, capturado y remitido al Exmo. Gobierno de la Provincia y en caso de fugarse tratado como montaraz y muerto. Después de un mes de la fecha, se tratara a los indios y chinas de las colonias indígenas encontrados sin licencia competente en los limites arriba señalados, como si fueran montaraces (AGPSF: A. de G. T.17, 1858, f. 208).

Al mismo tiempo quedaron marginados del proceso privatizador; incapaces, según la óptica de la época, de transformarse en buenos agricultores, en general no recibieron concesiones en propiedad $^{\mathrm{xvii}}$. La tierra que ocupaban, y que permanecía estéril en momentos en que crecía la demanda colonizadora, constituía un posible frente de expansión de la misma y no es extraño que tras ser expulsados de los territorios de las colonias y sus inmediaciones, los sauceros constituyeran una molestia incluso dentro de su propia reservación, por lo que el presidente Sarmiento insistía en su alejamiento (SARMIENTO, 1902, p. 288-289). Esto se verificó en parte en 1872 cuando la frontera avanzo hacia el norte y un numeroso grupo de sauceros fue trasladado a Reconquista.

\section{Consideraciones finales}

El conflicto fue la forma que adoptaron las relaciones interétnicas entre dos grupos culturalmente contrastantes, en el marco de la competencia por un mismo espacio planteada por las necesidades y aspiraciones de uno de esos dos conjuntos: el de los inmigrantes europeos. La estigmatización contribuyó a eliminar de la competencia regulada a uno de los grupos, definido por su origen étnico, justificando su marginalización efectiva y la violación del marco jurídico que a ese grupo sí se le imponía respetar.

Diferencias culturales y estigmatización étnica contribuyen a explicar las relaciones interétnicas signadas por la violencia en el contexto de la competencia por el espacio y los recursos, que en el fondo proviene de un desajuste entre el ideario de los promotores de la colonización y la realidad. 
Desde el Estado se consideraba territorio fiscal al antiguo dominio de los sauceros. Era su facultad, por lo tanto, vender o regalar esas tierras, que la escasez de poblaciones y el nulo desarrollo de la agricultura transformaban en desiertas según el punto de vista dominante. El fomento de la inmigración vendría a subsanar este problema; precisamente se ofrecía "suelo inhabitado" para colocar los excedentes de la población europea (DU GRATY, 1968, p. 25) que podía venir a ocuparlo con la garantía de acceder a la propiedad y contar con la protección del Estado.

Para los indios, por el contrario, no se trataba de tierras vacías e improductivas, y el derecho del Estado a disponer de las mismas no les resultaría un dato evidente, por lo menos en el inicio del proceso. Sin embargo, no se trataba simplemente de percepciones contrapuestas de un mismo espacio; los abipones estaban efectivamente allí.

\section{Referencias}

ALCARAZ, W. N. Aspectos de la población, inmigración, colonización agrícola y ferrocarriles en el desarrollo provincial. En: CONGRESO ARGENTINO DE INMIGRACIÓN. IV CONGRESO DE LA HISTORIA DE LOS PUEBLOS DE LA PROVINCIA, 2005, Esperanza. Asociación Amigos del Archivo Provincial, 2005.

ALEMÁN, B. Santa Fe y sus aborígenes, $2^{\text {a }}$ parte. Santa Fe: Librería El Foro, 1997.

ARECES, N. Los chacareros de la pampa gringa. $\mathrm{N}^{\circ}$ 23: La vida de nuestro pueblo. Buenos Aires: Centro Editor de América Latina, 1981.

AUZA, N. T. El ejército en la época de la Confederación1852-1861. Círculo Militar. 1971.

BARNARD, A. El sistema de pensamiento de los cazadores recolectores. En: BARNARD. Los pueblos cazadores recolectores. Tres conferencias dictadas en Argentina. Buenos Aires: Fundación Navarro Viola, 2001.

BARTH, F. Los grupos étnicos y sus fronteras. La organización social de las diferencias culturales. México: FCE, 1976.

BECK BERNARD, L. Cinco años en la confederación Argentina 1857-1862. Santa Fe: Imprenta Legislativa, 1991.

BERLI, S.; CAMARA, G. y ZURBRIGGEN, M. La incorporación del inmigrante suizo en la comunidad santafecina. Aportes para el estudio de la colonización en la zona centro-oeste de la Provincia de Santa Fe (1850-1940). Seminario de Historia argentina. Escuela Universitaria del Profesorado. Inédito. UNL, 1981. 
BUSO, N. y POGGI, M. Una argentina blanca y europea. La estigmatización étnica 18801910. En: X JORNADAS INTERESCUELAS/DEPARTAMENTOS DE HISTORIA, Rosario, septiembre 2005.

CALONI, V. Apuntes históricos sobre la fundación del Colegio de San Carlos y sus Misiones en la provincia de Santa Fe. Bs. As: Imprenta y librería de mayo, 1884.

CAVALlO, A. M. La colonia Esperanza. Frontera viviente. En: CONGRESO ARGENTINO DE INMIGRACIÓN. IV CONGRESO DE LA HISTORIA DE LOS PUEBLOS DE LA PROVINCIA, 2005, Esperanza. Asociación Amigos del Archivo Provincial, 2005.

COLOMBRES, A. La colonización cultural de la América Indígena. Quito: ED. del Sol, 1976.

CROLLA, A. Paradigmas de lectura y escritura comparadas: representaciones de la identidad "Gringo" en la literatura. En: CONGRESO ARGENTINO DE INMIGRACIÓN. IV CONGRESO DE LA HISTORIA DE LOS PUEBLOS DE LA PROVINCIA, 2005, Esperanza. Asociación Amigos del Archivo Provincial, 2005.

DU GRATY, A. La confederación argentina. Comisión nacional de Museos y monumentos históricos. 1968.

GORI, G. Colonización. Estudio histórico y social de la colonia de Humboldt. Santa Fe: Librería Colmegna, 1948. Inmigración y colonización en la Argentina. Buenos Aires: EUDEBA, 1964. El indio y la colonia Esperanza. Santa Fe: Ed. Colmegna, 1972. La Pampa sin gaucho. Buenos Aires: EUDEBA, 1986.

GSCHWIND J. J. Historia de San Carlos. T. 2. Concejo municipal S. Carlos Centro, 1994. HUTCHINSON, T. J. Buenos Aires y otras provincias argentinas. Buenos Aires: Ed Huarpes S. A., 1945.

LANCE, R. y PEDRONI, J. C. Raíces de San Jerónimo del Sauce. T III, Santa Fe: Imprenta Oficial, 1997.

Raíces de San Jerónimo del Sauce. T I, $2^{\circ}$ ed. Santa Fe: Imprenta Lux, 1999.

LÓPEZ ROSAS, J. R. Nicolás Denis, cacique indio y comandante militar. En: LÓPEZ ROSAS. Santa Fe. La perenne memoria. Santa Fe: Municipalidad de Santa Fe, 1993. 
MAC CANN, W. Viaje a caballo por las provincias argentinas. Buenos Aires: Imprenta Ferrari Hermanos, 1939.

MANTEGAZZA, P. Viajes por el Río de la Plata y el interior de la Confederación Argentina. Universidad de Tucumán. Buenos Aires. Imprenta y Casa Editora de Coni Hermanos, 1916.

OGGIER, G. y JULLIER, E. Historia de San Jerónimo norte. T. I. Rosario: editorial Apis, 1984.

OLIVELLO DE NEDER, L. Inmigración y colonización italiana en la provincia invencible. En: CONGRESO ARGENTINO DE INMIGRACIÓN. IV CONGRESO DE LA HISTORIA DE LOS PUEBLOS DE LA PROVINCIA, 2005, Esperanza. Asociación Amigos del Archivo Provincial, 2005.

ROSELli, M. Desde "El Rey" hasta el paralelo 28. En: Junta Provincial de Estudios Históricos de Santa Fe, Revista n LIII, 1983.

SARMIENTO, D. F. Obras. Papeles del Presidente 1868-1874. Primera parte. Buenos Aires: Establecimiento Poligráfico Marquez, Zaragoza y Cía., 1902.

\section{Fuentes Consultadas}

- AGPSF. Archivo General de la Provincia de Santa Fe:

A. de G. Archivo de Gobierno. Diversos tomos.

Archivo privado de José Rodríguez.

Copiador de notas del Ministerio de Gobierno, T.51, 1868-70.

Expedientes Criminales. Diversos tomos.

Archivo Topográfico. Diversos tomos.

- Arzobispado de Reconquista:

Libros Parroquiales del Arzobispado de Reconquista.

- Iglesia de San Jerónimo Norte:

Libros Parroquiales de San Jerónimo del Sauce.

- www.familysearch.org:

Argentina, censo nacional, 1869. Database with images. FamilySearch. http://FamilySearch.org; 14 june 2016. Citing Archivo General de la Nación, Buenos Aires. Argentina, censo nacional, 1895. Database with images. FamilySearch. http://FamilySearch.org; 21 august 2017. Citing Archivos Nacionales, Buenos Aires. 


\title{
Notas
}

\begin{abstract}
i En Argentina se llama "gringos" a los inmigrantes europeos no españoles y el término tiene una connotación positiva y afectiva (ARECES, 1981) Los "gringos" serán los actores centrales de la colonización agrícola de las llanuras santafesinas, que comienzan a ser conocidas como la "pampa gringa".

ii "Si nos concretamos a lo que es socialmente efectivo, los grupos étnicos son considerados como una forma de organización social. De acuerdo con esto, el rasgo crítico es (...) la característica de autoadscripción y adscripción por otros. Una adscripción categorial es una adscripción étnica cuando clasifica a una persona de acuerdo con su identidad básica y más general, supuestamente determinada por su origen y su formación. En la medida en que los actores utilizan las identidades étnicas para categorizarse a sí mismos y a los otros, con fines de interacción, forman grupos étnicos en este sentido de organización. Aunque las categorías étnicas presuponen diferencias culturales, es preciso reconocer que no podemos suponer una simple relación de paridad entre las unidades étnicas y las similitudes y diferencias culturales. Los rasgos que son tomados en cuenta no son la suma de diferencias "objetivas", sino solamente aquellas que los actores mismos consideran significativas" (BARTH, 1976, p. 15).

iii Libros Parroquiales del Arzobispado de Reconquista. Libro de Matrimonios I, Actas: 119, 197, etc. Libro de Defunciones I, Actas: 6, 14, 43, 74, etc. El marbete de "abipon" también aparece en actas parroquiales de San Jerónimo del Sauce o de otras reducciones durante la segunda mitad del s. XIX; e incluso era usado por algunos individuos como patronímico.
\end{abstract}

${ }^{\text {iv }}$ Lance y Pedroni (1997); reproducen, por ejemplo, el testimonio oral de Rosario Casco, una de las ultimas descendientes de abipones sauceros, donde se ve que Piedra Blanca era uno de sus terrenos de caza predilectos. En numerosos documentos del AGPSF se alude a actividades de caza desarrolladas por sauceros y a los lugares en que se practicaban, por ejemplo: en A. de G. T. 27, 1865, f. 1447, se menciona a los hijos del cacique Denis "corriendo avestruces" en la zona de la cañada del "Canton biejo del durasno" y "la cañada del Chagá" al oeste del Sauce.

${ }^{v}$ Nota del 18 de noviembre de 1869. Se refiere a Feliciano Denis, hijo de Nicolás Denis y jefe de los indios.

vi Como el caso de Manuel Acosta, mencionado en el texto, casado con María Lobroquin, Alvarez o Ramírez (abipona); se trata de la misma persona que aparece con estos diferentes apellidos en las actas parroquiales; $\mathrm{L}$. Bautismos; 1857/24, 1861/2, etc. L. Defunciones; 1873/51. Libros parroquiales de San Jerónimo del Sauce, Iglesia de San Jerónimo Norte.

vii Consultados en: www.familysearch.org

viii AGPSF, Archivo Privado de José Rodríguez, Caja 1, Legajo O, f. 2: en nota del 7 de mayo de 1854 el capitán Matías Olmedo informa que hubo pelea entre los soldados dragones y que Balentín Allala y Apolinario Galban mataron a Leandro Bayo. AGPSF, A de G. T 20, 1860, f. 488: en Notas del jefe de policía de la capital, se comunica, en noviembre de 1860 , que fue detenido y puesto a disposición del juez de primera instancia el sargento Bautista Riquelme por la muerte de José Frutos, ambos indios lanceros, como se desprende de las listas de revista del Sauce. AGPSF, A de G. T 23, 1862-63, f. 1193, y en Expedientes Criminales 1863, 1-32; se informa sobre la detención de Custodio Gómez, santafesino, por herir en una riña a Juan Alvarado, entrerriano. AGPSF, Expedientes Criminales 1869, 24-58 y en Libro de defunciones de San jerónimo del Sauce: sobre el asesinato de Ambrosio Mambrú, chileno, en una pulpería en 1868, por Tomas Maturana o Maturango clasificado como "blanco" en actas parroquiales -. Etc.

ix Como el matrimonio de José Calderón (cordobés), de la estancia de José Pereira y Venancia Suarez (saucera), Acta: 1860/2; o el matrimonio de Mauricio Ríos (saucero) y Rosario Farías (cordobesa), vecina de la estancia de Freyre, Acta: 1866/62, etc. Libro de matrimonios de San Jerónimo del Sauce, Iglesia de San Jerónimo Norte.

\begin{tabular}{l|l} 
Revista RBBA & Revista Binacional Brasil Argentina
\end{tabular} 
${ }^{x}$ Como el caso de los ya mencionados José Manuel Acosta y su esposa María Lobroquin que en octubre de 1861 apadrinaron a un hijo de Severa Brochero (criolla) y de José Manuel Crespo (indio), padrino a su vez de dos hijos de los primeros. L. Bautismos; Actas: 1857/24, 1861/2, 1861/15. Libros parroquiales de San Jerónimo del Sauce, Iglesia de San Jerónimo Norte.

xi Buso y Poggi (2005) señalan que: “...la descripción de los habitantes de la zona del río Salado y del Chaco que realiza Amadeo Jacques publicada en 1897 señala los estrechos cerebros, la desmesurada distancia y anchura de pómulos, las mandíbulas fuertes y salientes y la casi ausencia de frente que, considera ni siquiera corresponde a los animales más avanzados de la escala zoológica".

xii Constancio Ferrero, decía de los indios, que "...Pesa sobre su cerebro una especie de inercia fatal y misteriosa que condena su pensamiento a replegarse sobre si mismo y a no traspasar ciertos límites..." (Citado en Beck Bernard, 1991).

xiii Crolla (2005); muestra los derroteros de la connotación de la categoría "gringo" en la literatura argentina hasta llegar a la valoración sumamente positiva presente en escritores de la región en el s. XX, y en el imaginario colectivo. Trabajos de tipo historiográfico como los de Gori (1986), Alcaraz (2005), Cavallo (2005); Olivello de Neder (2005), etc. señalan tópicos como los "espacios vacíos"; las "inmensas dificultades"; el "esfuerzo" y "trabajo tesonero" de los inmigrantes, etc.

xiv Las quejas y denuncias contra hacendados y peones gauchos eran frecuentes: AGPSF, A. de G. T. 21, 1861, f. 889. A. de G. T. 42,1875 , fs. 1120,1239 , etc.

${ }^{x v}$ En: AGPSF, A. de G. T. 20, 1860, f. 1179, el estanciero Sañudo denuncia a los colonos de San Carlos. A. de G. T. 21, 1861, f. 943, el estanciero José Rodriguez denuncia a los de la misma colonia, etc.

xvi Por ejemplo en: AGPSF, A. de G. T. 20, 1860, f. 589.

xvii La entrega de títulos de propiedad de la tierra a los indígenas, cuando no fue negada fue dilatada por la vía burocrática. En el censo de 1895, de los 66 pobladores del Sauce que identificamos como indígenas, solo 27 figuran con propiedad raíz. Mientras en la zona rural, solo 19 sauceros figuran con propiedad raíz, frente a 79 extranjeros que la tienen. Advertimos, además, una pérdida de esas propiedades, en beneficio de criollos y extranjeros, por vía legal. AGPSF. Topográfico T. 22, f. 179: en 1888 Manuel Caminos pide título de propiedad de terrenos, en el pueblo, que compro a Jacinta Ríos y Juana Ríos (sauceras). T. 27, f. 248: en la mensura de 1891, Federico Perren presenta títulos de las chacras 26, 27, 28, entre otras, pertenecientes antes a Nicolás Rivero, Cayetano Leiva y Nicolás Álvarez (sauceros), como se ve al cruzar estos datos con la información del Libro de Notas al exmo Gob. y Juzgado, T. 44, f. 251. Etc.

\section{Sobre el autor}

Profesor de Historia, egresado de la Facultad de Humanidades y Ciencias. Universidad Nacional del Litoral. Se ha desempeñado como Ayudante de cátedra dedicación simple suplente en las cátedras: "Sociedades del Cercano Oriente", "Formación del mundo Afro-asiático" y "Problemáticas contemporáneas de Asia y África" de la carrera de Historia, FHUC, UNL. Autor y coautor de ponencias y artículos sobre historia de los pueblos indígenas.

Recebido: 06.07.18

Aprovado: 26.07 .18 